\title{
Pepper Plants Leaf Spectral Reflectance Changes as a Result of Root Rot Damage
}

\author{
Shahar Weksler ${ }^{1,2, *}$, Offer Rozenstein ${ }^{2}$, Nadav Haish ${ }^{3}$, Menachem Moshelion ${ }^{3}{ }^{\circ}$, Rony Wallach ${ }^{4}$ \\ and Eyal Ben-Dor 1 \\ 1 Porter School of Environment and Earth Sciences, Faculty of Exact Sciences, Tel Aviv University (TAU), \\ Tel Aviv 6997801, Israel; bendor@tauex.tau.ac.il \\ 2 Institute of Soil, Water and Environmental Sciences, Agricultural Research Organization, \\ Rishon LeZion 7528809, Israel; offerr@volcani.agri.gov.il \\ 3 The Robert H Smith Institute of Plant Sciences and Genetics in Agriculture, The Hebrew University of \\ Jerusalem, Rehovot 7610001, Israel; nadav.haish@mail.huji.ac.il (N.H.); \\ menachem.moshelion@mail.huji.ac.il (M.M.) \\ 4 Department of Soil and Water Sciences, The Robert H. Smith Faculty of Agriculture, Food and Environment, \\ The Hebrew University of Jerusalem, Rehovot 76100, Israel; rony.wallach@mail.huji.ac.il \\ * Correspondence: weksler@mail.tau.ac.il; Tel.: +972-3-640-5679
}

Citation: Weksler, S.; Rozenstein, O.; Haish, N.; Moshelion, M.; Wallach, R.; Ben-Dor, E. Pepper Plants Leaf Spectral Reflectance Changes as a Result of Root Rot Damage. Remote Sens. 2021, 13, 980. https://doi.org/ $10.3390 /$ rs13050980

\section{Academic Editor:}

Arturo Sanchez-Azofeifa

Received: 16 December 2020

Accepted: 25 February 2021

Published: 4 March 2021

Publisher's Note: MDPI stays neutral with regard to jurisdictional claims in published maps and institutional affiliations.

Copyright: (c) 2021 by the authors. Licensee MDPI, Basel, Switzerland. This article is an open access article distributed under the terms and conditions of the Creative Commons Attribution (CC BY) license (https:// creativecommons.org/licenses/by/ $4.0 /)$.

\begin{abstract}
Symptoms of root stress are hard to detect using non-invasive tools. This study reveals proof of concept for vegetation indices' ability, usually used to sense canopy status, to detect root stress, and performance status. Pepper plants were grown under controlled greenhouse conditions under different potassium and salinity treatments. The plants' spectral reflectance was measured on the last day of the experiment when more than half of the plants were already naturally infected by root disease. Vegetation indices were calculated for testing the capability to distinguish between healthy and root-damaged plants using spectral measurements. While no visible symptoms were observed in the leaves, the vegetation indices and red-edge position showed clear differences between the healthy and the root-infected plants. These results were achieved after a growth period of 32 days, indicating the ability to monitor root damage at an early growing stage using leaf spectral reflectance.
\end{abstract}

Keywords: reflectance; root rot; transpiration; red-edge

\section{Introduction}

Plants may be damaged by biotic stress such as fungi, bacteria, viruses, or nematodes, or abiotic stress such as drought, salinity, extreme temperature, or physical damage [1]. Both biotic and abiotic stress in plants may damage different tissues and organs of the plant. The primary role of roots is to absorb water and minerals to support the shoot demands. Any limitation of the root capabilities will reduce shoot productivity and eventually yield [2]. Moreover, prolong biotic or abiotic root rot disease reduces plant health and may eventually kill the plant $[3,4]$. Healthy roots are generally white and firm, while decayed roots may be darker, smaller, and contain mucus. Root rot severity depends on abiotic factors such as soil compaction, low oxygen level, unsuitable $\mathrm{pH}$, irrigation patterns, and temperature $[5,6]$. Soilborne pathogens generally cause root rot disease induced by biotic factors, mainly fungi, spread through infected irrigation equipment and may infect different organs $[7,8]$.

Remote sensing and imaging spectroscopy can monitor vegetation status from the leaf scale through the canopy to the field scale. It has advanced our ability to understand and optimize agricultural processes by estimating growth variables that change throughout the season, such as pigment concentration, leaf area index, or yield. The most direct measurement is a contact measurement using a spectrometer that measures the light emitted from a synthetic light source and reflected from the leaf. These measured spectra can later be compared with spectra collected from afar, which typically contain artifacts from sun illumination, atmospheric effects, and viewing angles [9,10]. One key factor in analyzing 
vegetation is the red-edge in the reflectance domain. The red-edge is the transition between the strong absorbance in the red region by Chlorophyll (Chl) pigment and the relatively high reflectivity in the NIR region attributed to the scattering effect caused by the internal leaf structure [11,12]. The red-edge position (REP) is defined as the wavelength at the inflection point of the reflectance spectrum across the red-edge domain (690 nm-740 nm) [12]. It is mainly affected by the leaf $\mathrm{Chl}$ content and internal leaf structure and is less sensitive to canopy variability [13]. In healthy plants, the REP shifts to longer wavelengths with the increase in Chl. Accordingly, REP is used to monitor plant growth stages and stress status of the plant, as it also shifts to longer wavelengths as leaves mature until the onset of senescence, when a reverse trend may be observed [11]. REP was also shown to be affected by plant diseases [14], heavy metals [11], water stress [15,16], and nutrient deficiency [17]. In the past few years, the REP was a key factor in monitoring forest canopies, creating land cover maps, crops yield estimations, and foliar pests infection [9,18-22]. As the exact REP position is crucial, it is best extracted when a high spectral resolution sensor is used, allowing for the detection of small changes.

Vegetation analysis by remote sensing data is also carried out using vegetation indices based on selected bands and wavelengths [23]. Vegetation indices are typically calculated from two or three bands, either narrowband or broadband $[23,24]$. The most cited index is the normalized difference vegetation index (NDVI), enhancing the signal of green vegetation and tracking seasonal changes driven by plant growth and decline. Many other vegetation indices are established, each developed to tackle different remote sensing obstacles and utilize different parts of the spectrum. Vegetation is also monitored using point and imaging spectroscopy sensors, where the high spectral resolution is exploited to estimate chemical composition and physiological processes using spectral tools ([25-27]).

There are many reports on REP and VI use in vegetation monitoring; however, information on spectral changes caused by root damage are very few [28-30] and are typical of wilted or dead samples. The current manuscript presents whole-plant physiological measurements under controlled conditions of pepper plants and their leaf spectral measurements. Some plants suffered from unexpected root rot disease. Accordingly, this study analyzes and reports the spectral changes associated with the damage to those specific infected plants.

\section{Materials and Methods}

Four-week-old seedlings of 72 pepper plants (Capsicum annum) were transplanted to pots and grown in a greenhouse [31] during April 2019, at the Hebrew University, at the Faculty of Agriculture in Rehovot, Israel. A fertigation experiment was designed to test potassium's effect on plant performance using continuous physiological measurements, with the added effect of salinity, known to reduce yield. The 72 plants were divided into eight plants per group. Each group was given different treatments from the combination of three potassium levels (low, control, high) and three levels of salinity (water, medium, and high). Potassium levels of 30 PPM, 105 PPM, and 180 PPM were administered to the low, control (optimal), and high treatments, respectively. The salinity treatments were $\mathrm{H}_{2} \mathrm{O}, 0.03 \mathrm{M} \mathrm{NaCl}$, and $0.05 \mathrm{M} \mathrm{NaCl}$. The pots' weight was logged every three minutes by computerized weighing lysimeters, using PlantArray 3.0 (www.plantditech.com). The system was used to calculate the daily plant weight and daily transpiration [32]. The plant weight was calculated by reducing the pot and growing medium weight from the final weight. The pots were covered with a custom cap that only allowed the shoot stem through it, which enabled us to determine the daily transpiration. The irrigation was only applied at night. Thus, the daily transpiration was calculated as the weight difference between the early morning weight and the evening weight; no irrigation was applied during that time. PlantArray 3.0 was also used for logging daily photosynthetic active radiation (PAR) and vapor pressure deficit (VPD).

Although the growing period of pepper may be six to eight months, the fertilization experiment enabled capturing a full physiological response profile in a few weeks, thus 
it was terminated after 32 days. Then, the plants' stems were cut above the first node and photographed. Each plant's roots were washed in fresh water to remove the growing medium residues (quartz sand). The roots were found to have ranging degrees of root rot disease, as seen in Figure 1. Judging the roots by their color (light to dark), size, and mucosity, they were categorized into six levels of root damage, from r0 (no damage) to $\mathrm{r} 5$ (severe damage) by an expert agronomist. Very few samples were classified as $r 1-r 3(n=5)$; many were severely infected ( $\mathrm{r} 4-\mathrm{r} 5, \mathrm{n}=19)$, and the majority of plants were classified as not infected $(n=38)$. Several plants $(n=10)$ did not transplant well and were removed from the analysis. Figure 1 presents an example of each category and summarizes the strict root rot category from $\mathrm{r} 0$ to $\mathrm{r} 5$. The roots were dried in an oven at $65^{\circ} \mathrm{C}$ for $48 \mathrm{~h}$. After the roots were dry, the weight of each root was measured.

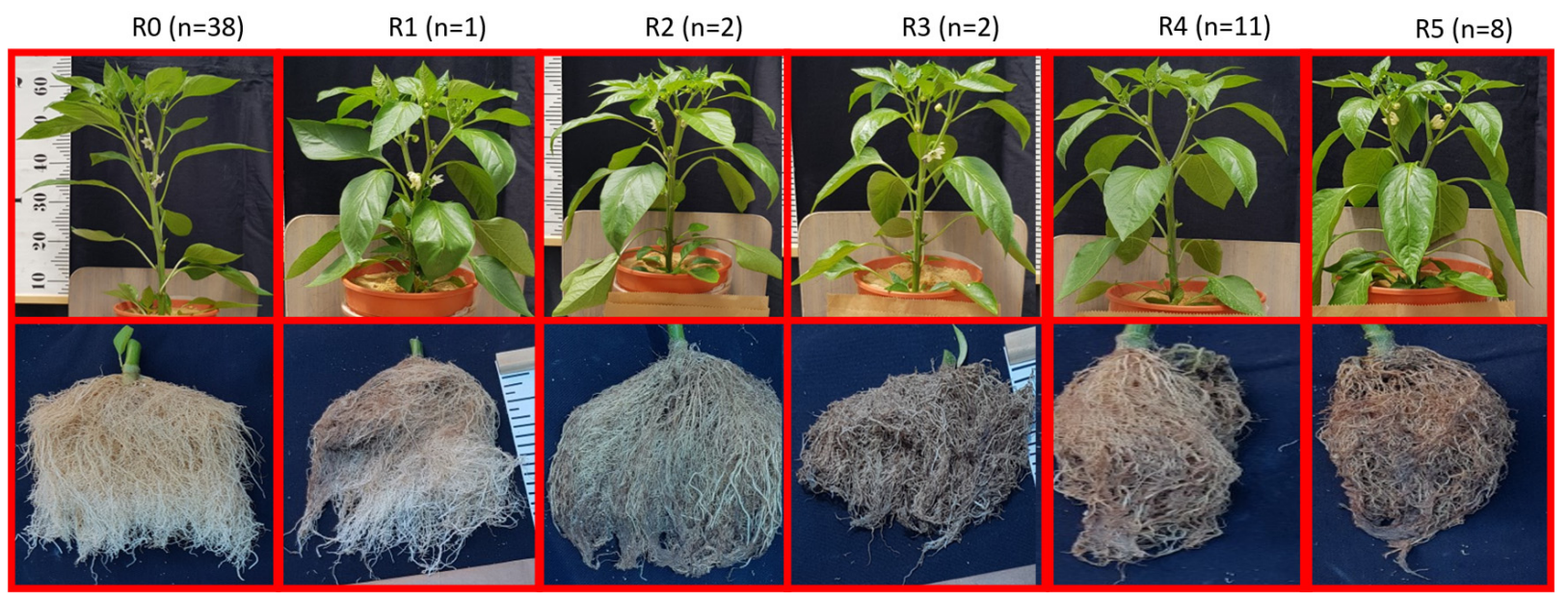

Figure 1. Representative image of fresh shoots and roots from six levels of root rot disease. Leftmost pair: healthy root (r0). Rightmost: most damaged root (r5). The number of plants per group is depicted on the top row. Images were taken on the last day of the experiment (32 days after transplanting to the pots).

\section{Spectroscopic Measurements and Spectral Processing}

At the end of the experiment, the three youngest fully grown leaves were selected from each plant. Before the roots were cut, the leaves were cut and immediately measured by an ASD FieldSpec-Pro and a contact probe [10]. The leaves were gently pressed (without compression) between a black surface and the contact probe's lens. Each leaf was measured in three different spots, resulting in nine spectral measurements per plant that were averaged to represent one representative spectral reflectance per plant [33,34]. Reflectance was calculated by calibrating the spectrometer against a white reference panel (Spectralon, Labsphere inc.) every five plants.

To check which spectral bands present significant differences in the reflectance values between the groups, an analysis of variance (ANOVA) was calculated [35]. The KruskalWallis test was used $(\alpha=0.05)$ when the ANOVA assumptions were not met (normality and homogeneity of variance). The mean plant reflectance spectrum was converted to the first derivative spectrum for locating the red-edge position, and the local maximum between 680 and $720 \mathrm{~nm}$ was registered for each plant.

The spectra were resampled to common bandwidths of the public domain Sentinel 2 bands using a Gaussian spectral response function (Table 1). Among other things, Sentinel 2 bands were carefully selected to monitor vegetation, and a multispectral sensor may be more straightforward and sufficient for low altitude imaging of plants infected with root rot. The resampling process enabled to check whether multispectral sensors may observe these differences among the plants' spectra, in addition to the very high spectral resolution recorded by the spectrometer. The significance of differences in reflectance between the groups was tested again using the resampled bands. In addition, six established vegetation 
indices were calculated (Table 2) and tested for their ability to separate the plants by their root damage level using ANOVA followed by the Tukey honestly significant difference post hoc test $(\alpha=0.05)$.

Table 1. The band centers used for resampling the ASD resolution.

\begin{tabular}{ccc}
\hline Sentinel 2 Band Index & Center Wavelength $(\mathbf{n m})$ & Bandwidth $(\mathbf{n m})$ \\
\hline Ultra-blue B1 & 442.7 & $432.2-453.2$ \\
\hline Blue B2 & 492.4 & $459.4-525.4$ \\
\hline Green B3 & 559.8 & $541.8-577.8$ \\
\hline Red B4 & 664.6 & $649.1-680.1$ \\
\hline Re1 B5 & 704.1 & $696.6-711.6$ \\
\hline Re2 B6 & 740.5 & $733-748$ \\
\hline Re3 B7 & 782.8 & $772.8-792.8$ \\
\hline Nir B8 & 832.8 & $779.8-885.8$ \\
\hline Nir_n B9 & 864.7 & $854.2-875.2$ \\
\hline SWIR1 & 1613.7 & $1567.2-1659.2$ \\
\hline SWIR2 & 2202.4 & $2114.9-2289.9$ \\
\hline
\end{tabular}

Table 2. The vegetation indices used in this study as calculated based on simulated Sentinel 2 bands configuration.

\begin{tabular}{|c|c|c|c|}
\hline Vegetation Index & Abbreviation & Formula & References \\
\hline $\begin{array}{c}\text { Normalized } \\
\text { difference vegetation } \\
\text { index }\end{array}$ & NDVI & $\frac{\rho B 8-\rho B 4}{\rho B 8+\rho B 4}$ & Tucker (1979) [36] \\
\hline $\begin{array}{l}\text { Green normalized } \\
\text { difference vegetation } \\
\text { index }\end{array}$ & GNDVI & $\frac{\rho B 9-\rho B 3}{\rho B 9+\rho B 3}$ & $\begin{array}{c}\text { Gitelson et al. (1996) } \\
\text { [37] }\end{array}$ \\
\hline $\begin{array}{l}\text { Red-edge normalized } \\
\text { vegetation index }\end{array}$ & RENDVI & $\frac{\rho B 6-\rho B 5}{\rho B 6+\rho B 5}$ & $\begin{array}{l}\text { Gitelson et al. (1994) } \\
\text { [38] }\end{array}$ \\
\hline $\begin{array}{l}\text { Modified chlorophyll } \\
\text { absorption in } \\
\text { reflectance }\end{array}$ & MCARI & $\begin{array}{c}(\rho B 5-\rho B 4)- \\
0.2(\rho B 5-\rho B 3)\left(\frac{\rho B 5}{\rho B 4}\right)\end{array}$ & $\begin{array}{c}\text { Daughtry et al. (2000) } \\
{[39]}\end{array}$ \\
\hline $\begin{array}{c}\text { Visible } \\
\text { Atmospherically } \\
\text { Resistant Index }\end{array}$ & VARI & $\frac{(\rho B 3-\rho B 4)}{(\rho B 3+\rho B 4+\rho B 2)}$ & $\begin{array}{c}\text { Gitelson et al. (2002) } \\
\text { [40] }\end{array}$ \\
\hline $\begin{array}{l}\text { Sentinel } 2 \text { red-edge } \\
\text { position }\end{array}$ & S2REP & $\begin{array}{c}705+35((((\mathrm{~B} 7+\mathrm{B} 4) / 2)- \\
\mathrm{B} 5) /(\mathrm{B} 6-\mathrm{B} 5))\end{array}$ & $\begin{array}{c}\text { Frampton et al. } 2013 \\
{[41]}\end{array}$ \\
\hline
\end{tabular}

\section{Results and Discussion}

All the treatments, except for one (the combination of low potassium levels and high salinity), were found to have both healthy and diseased plants (Figure 2, Table 3). The absence of diseased plants in this treatment is attributed to a chance occurrence, as both low potassium and high salinity in other treatments were infected. 


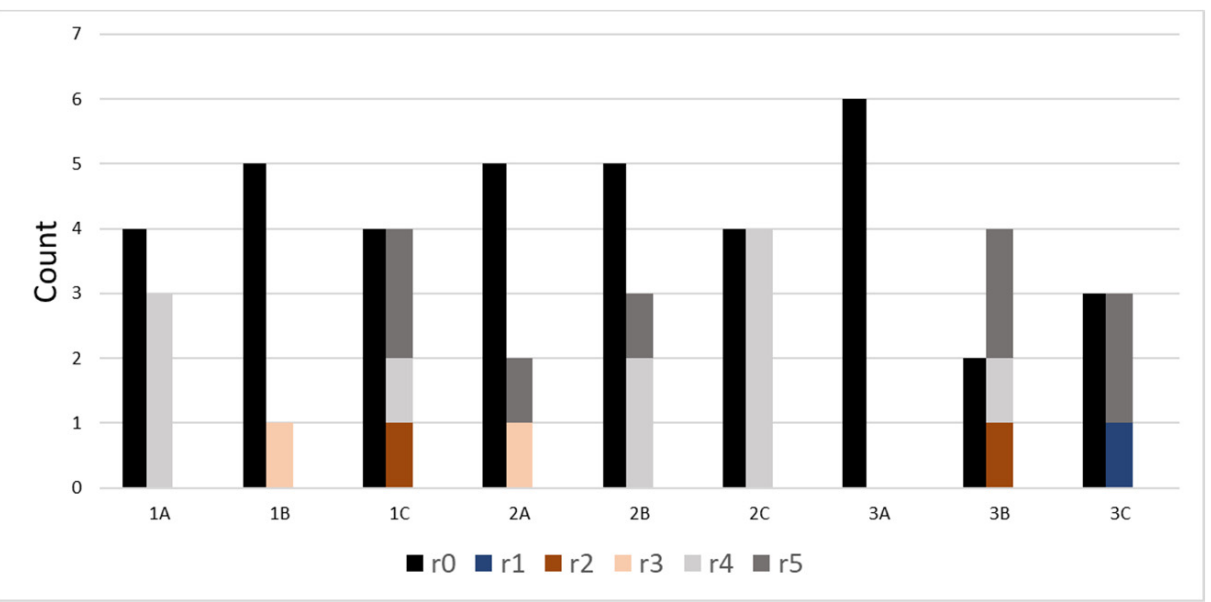

Figure 2. The number of plants per treatment that were healthy or diseased.

Table 3. Plant treatments.

\begin{tabular}{cc}
\hline ID & Treatment \\
\hline $1 \mathrm{~A}$ & Low potassium $+\mathrm{H}_{2} \mathrm{O}$ \\
\hline $1 \mathrm{~B}$ & Medium potassium $+\mathrm{H}_{2} \mathrm{O}$ \\
\hline $1 \mathrm{C}$ & High potassium $+\mathrm{H}_{2} \mathrm{O}$ \\
\hline $2 \mathrm{~A}$ & Low potassium + medium salinity \\
\hline 2B & Medium potassium + medium salinity \\
\hline 2C & High potassium + medium salinity \\
\hline $3 \mathrm{~A}$ & Low potassium + high salinity \\
\hline 3B & Medium potassium + high salinity \\
\hline $3 \mathrm{C}$ & High potassium + high salinity \\
\hline
\end{tabular}

Grouping the plants' weight based on their disease level revealed that the high severity of the root damage $(\mathrm{r} 4, \mathrm{r} 5)$ significantly affected the final plant's weight since it inhibited their ability to grow in size by reducing their water uptake from the growing medium (Figure 3A). The differences in plant mean weight and the roots dry weight (Figure 3B) indicate that the disease had started during the early stages of the experiment. If the condition was less advanced, its effects would likely be less severe and would not significantly differ between the groups. This inhibition is also observed in Figure 4, which depicts the plants' daily transpiration by damage levels and daily PAR and VPD changes. The infected plants had a significantly lower final weight, and their daily transpiration was also lower from day 14 until the end of the experiment. The small sample size of non-severe root damage $(\mathrm{r} 1-\mathrm{r} 3)$ indicates that these plants were probably damaged late during the experiment instead of r4-r5 plants. Figure 4 shows how healthy and infected plants' daily transpiration responded to changes in the ambient conditions, that is, on days 13 and 30, as the PAR and VPD were low in the greenhouse.

Comparing the mean spectra of the infected and healthy plant groups shows a minor spectral difference, both in the high resolution and the resampled lower resolution. However, these minor spectral differences are significant in the visible and red-edge portions of the spectrum but not for any other bands (Figure 5). Although the damage affected the roots, the spectra of groups $\mathrm{r} 4-\mathrm{r} 5$ show the highest reflectance in the green region, and r5 has the lowest reflectance from the NIR plateau $(\sim 750 \mathrm{~nm})$ to the upper limit of the ASD spectral region $(2500 \mathrm{~nm})$. The spectral differences between the different root damage groups demonstrated by the high spectral resolution of the ASD spectrometer were not lost when the spectra were resampled to a lower spectral resolution: the bands between 450 
and $750 \mathrm{~nm}$ were significantly different between the groups, but bands outside this region, namely B1 and B7-B11, were not different. Moreover, the groups' red-edge position shows a significant decrease towards lower wavelengths by $5-6 \mathrm{~nm}$ from healthy to infected plants (Figure 6). This is in agreement with previous findings by Milton et al. [42], where stressed plants treated with high concentration arsenic or selenium treatments exhibited similar spectra.

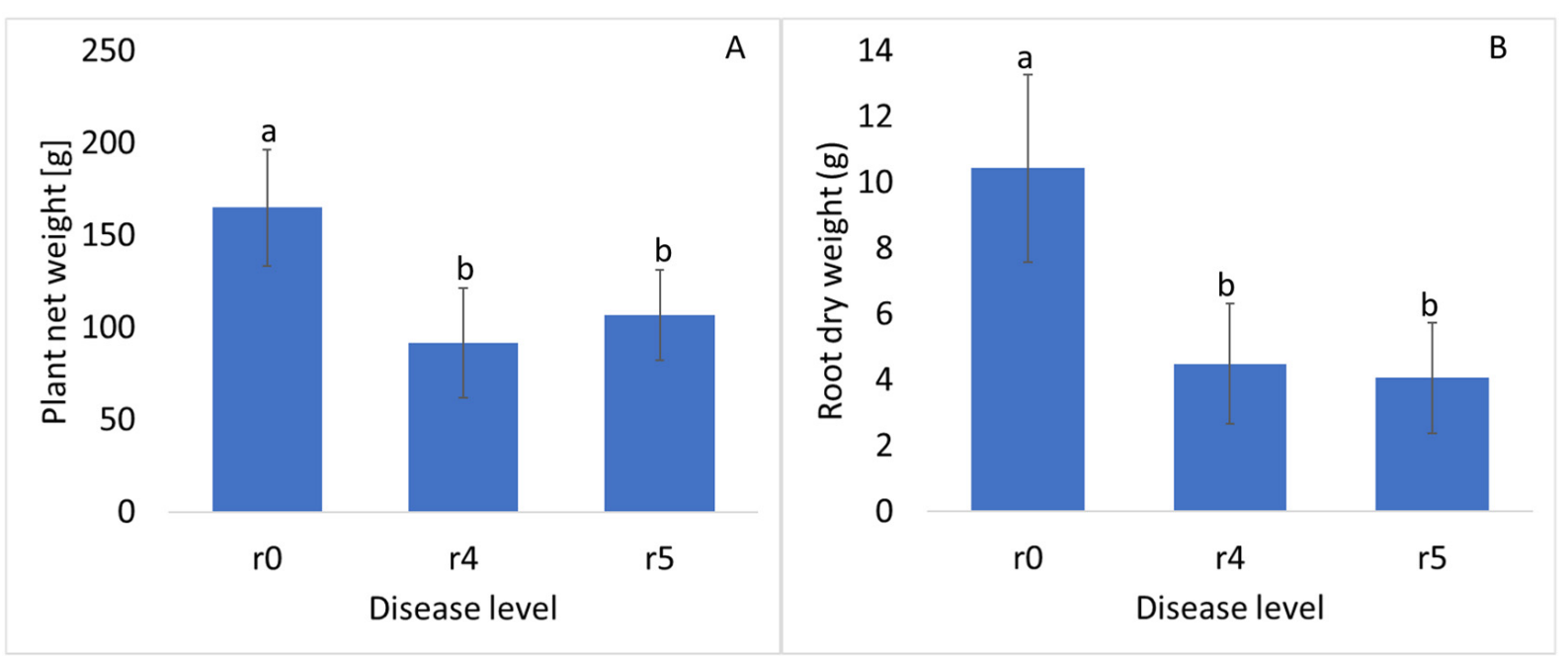

Figure 3. Plants net weight (A) and root dry weight (B) on the last day of the experiment. Error bars represent standard deviation. Significant differences $(p<0.05)$ are marked with different letters.

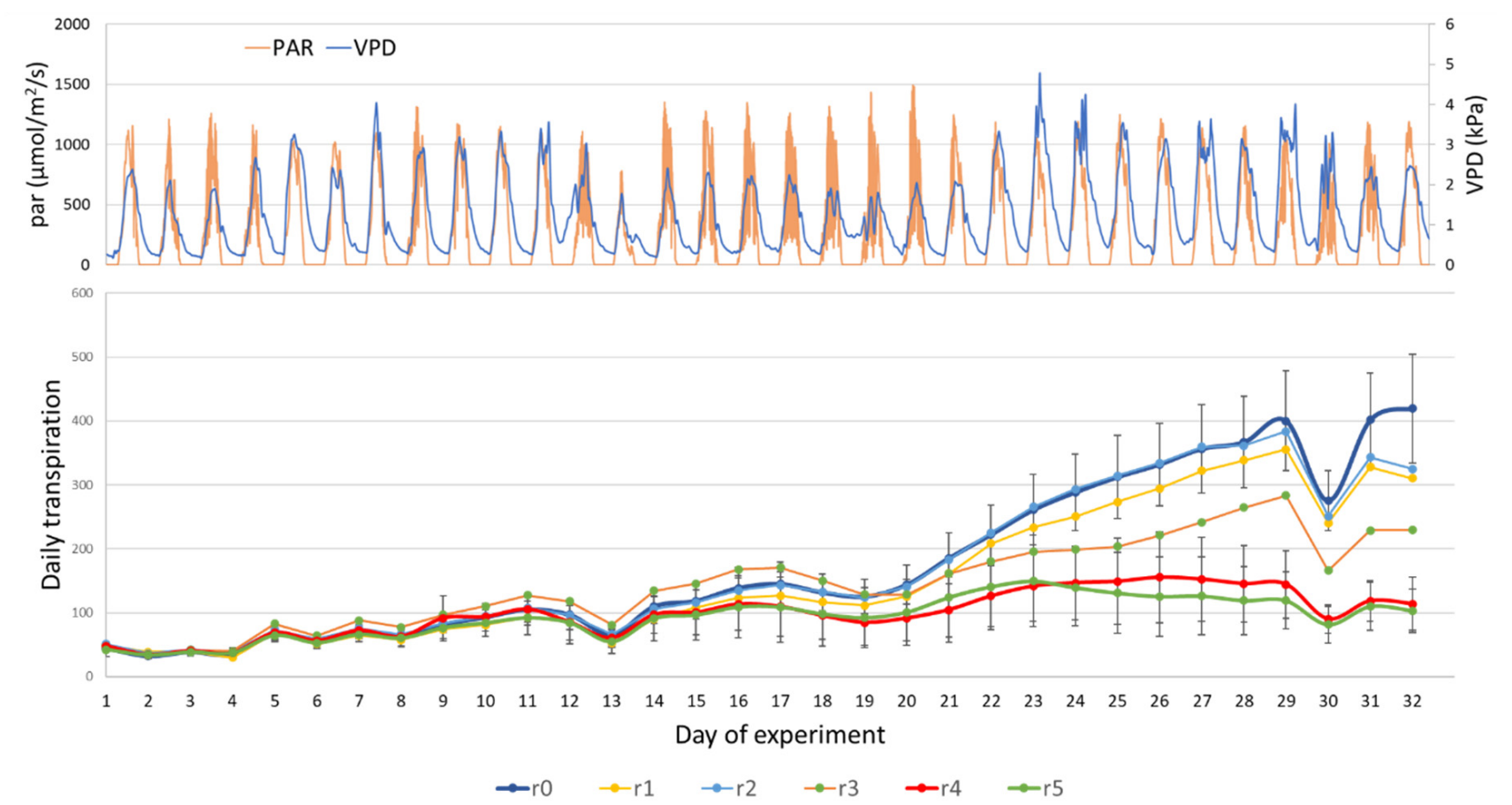

Figure 4. Top: Photosynthetic active radiation (PAR) and vapor pressure deficit (VPD) of the entire experiment. Bottom: Daily transpiration by root damage level throughout the experiment. Healthy (r0) plants are significantly different from damaged plants $(\mathrm{r} 4, \mathrm{r} 5)$ from day 14 until the end of the experiment $(p<0.05) .{ }^{*} \mathrm{r} 1, \mathrm{r} 2, \mathrm{r} 3$ do not have error bars since they have less than three samples. 

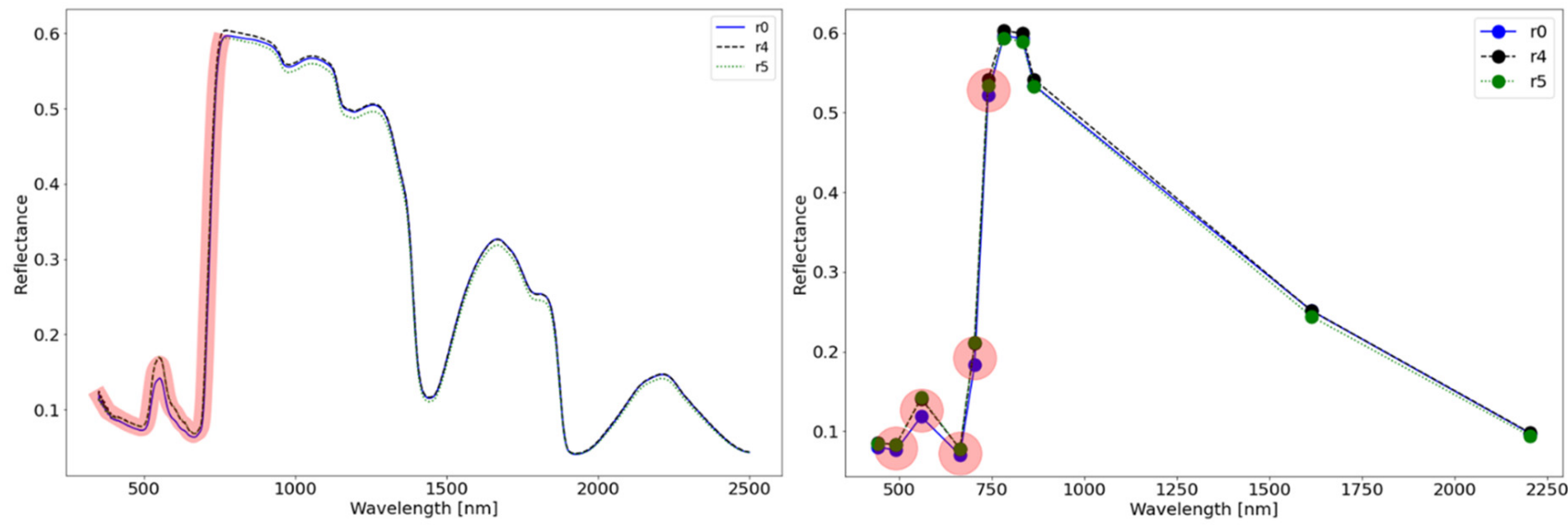

Figure 5. A: Mean reflectance spectrum of healthy (r0) and severely diseased plants (r4,r5); B: Resampled spectra to Sentinel 2 bands. Significantly different band values $(p<0.05)$ between the groups are shaded by a red color.
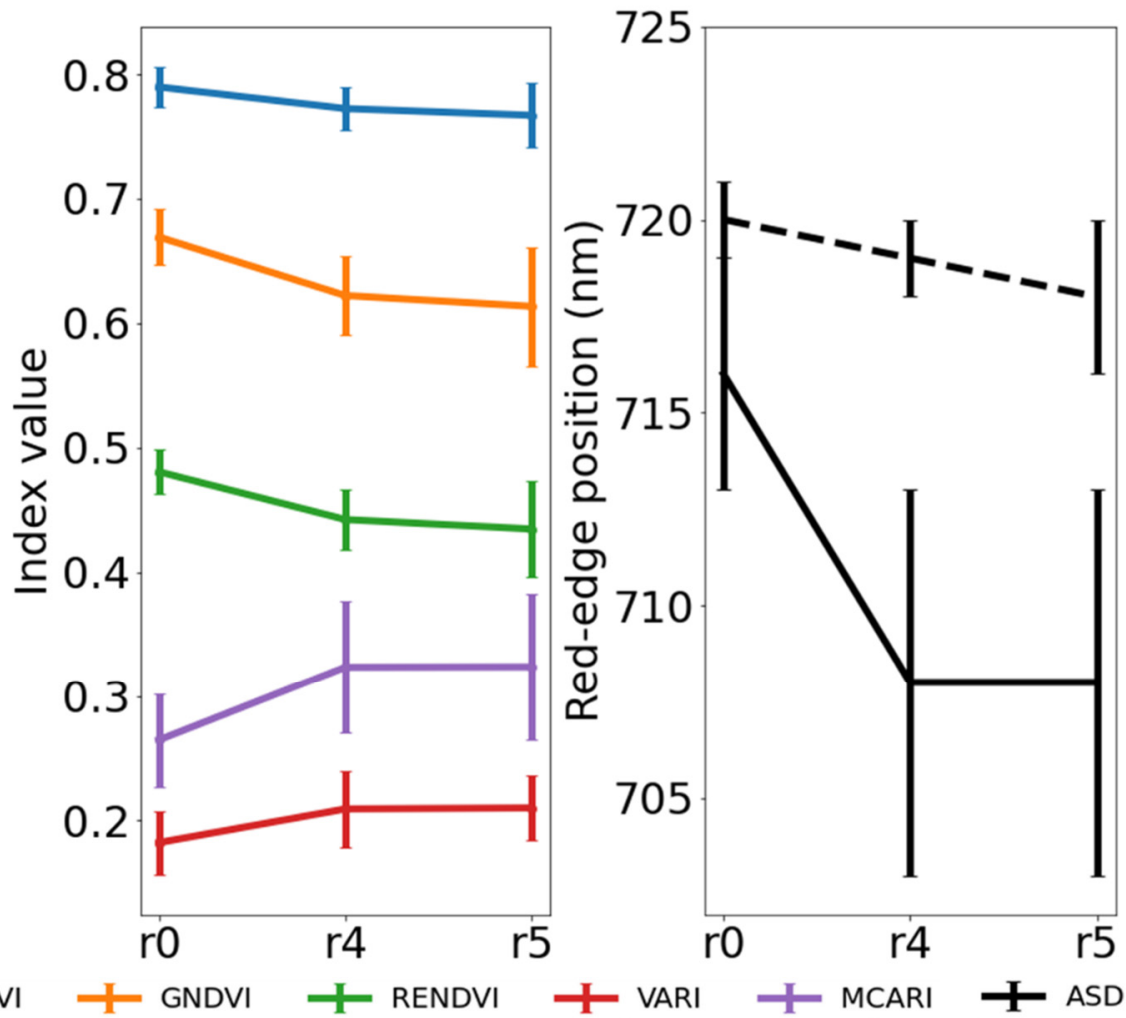

H- S2REP

Figure 6. Left: Mean indices values and standard deviations for each root damage level. Right: Mean red-edge position and standard deviations for each root damage level. Note: Different letters mark a significant difference between the groups $(p<0.01)$.

All the calculated VIs could separate $\mathrm{r} 0$ from $\mathrm{r} 4$ or $\mathrm{r} 5$ groups, based on the mean index value (Figure 6). In comparison, separating between $\mathrm{r} 4$ and $\mathrm{r} 5$ was not possible with any of the calculated VI.

The most sensitive VI is MCARI, which has the highest slope between the r0 mean value and $\mathrm{r} 4$. In addition, MCARI and VARI show a positive association with the increase in damage level, as opposed to the other VIs that show a negative association.

$\mathrm{Chl}$ content in leaves is known to change from low to high content as leaves mature $[12,25,43]$. This variance in Chl content is linearly correlated with a shift in REP. Differences in REP (up to $10 \mathrm{~nm}$ ) were previously reported to be the results of different 
diseases such as yellow mosaic disease [14] and two-spotted spider mite damage [22]. Additionally, water stress was also reported to cause a shift in the REP in maize [15] and a general decrease in the infrared channel in citrus trees affected by footrot [44]. While these shifts are the results of plant shoot changes, the RE shift reported in this research was not associated with any noticeable visual symptoms.

On the contrary, the REP was associated with the root damage. During the experiment, daily visual inspection of the leaves did not detect any visual symptoms. Moreover, routine inspection of the plants' daily transpiration using the logged values hinted that several of the plants have abnormal values. These abnormalities were verified at the end of the experiment.

The REP of healthy and damaged plants was significantly different using the high spectral resolution data, and VI could be similarly calculated from the resampled data to express these differences. Nonetheless, the resampling to the lower spectral resolution of Sentinel 2 proved that even a few bands are sufficient to detect abnormalities when a naked eye cannot. Nevertheless, the REP in the resampled spectra that was estimated using the Frampton et al. [41] method was several nanometers higher than the original highresolution spectra. Similarly, the sensitivity between $\mathrm{r} 0$ and $\mathrm{r} 4$ was lower in the resampled spectra. Current multispectral technology is continually getting cheaper, and unmanned aerial vehicles (UAV), amongst other remote sensing means from the air and orbit domain, are exploited for precision farming and phenotyping practices. It is not unlikely that in the near future, in addition to nutrient deficiencies being detected from leaves' spectral signal, root disease may also be detected in early growing stages, as demonstrated here. Using the leaves spectral signature as an antenna to account for root zone conditions is not a new idea. As Zhang et al. [45] demonstrated, soil salinity at the root zone can be inferred by the canopy's spectral response using high spectral resolution data. This study proposed a method to detect the root status under several root zone conditions (nutrient and salinity content) using the leaves spectral signals.

\section{Conclusions}

This study focused on the potential to identify root damage using high and multispectral resolution during the early stages of a growing season. It was the first to bring proof of concept and demonstrate early-stage spectral reflectance changes caused by root malfunctioning. Although the leaves did not show any noticeable visible change during the experiment, as an indication of the underground disease development, the measured daily transpiration declined with disease development, and the final plant weight was lower for damaged plants. Additionally, the red-edge shift agreed with these trends. The VIs calculated were significantly different between the damaged plants and healthy ones based on the spectrum alone and were supported by the bio-physiological measurements (root dry weight, daily transpiration, and plant weight).

VIs are typically used to track plant growth and development by correlating the indices with biophysical data such as pigment content. However, in a scenario where everything seems normal and a spectral change is obtained, root disease may be discovered early on and treated before significant damage to the plants and yield occurs.

Author Contributions: Conceptualization, M.M., R.W. and E.B.-D.; Formal analysis, S.W.; Funding acquisition, R.W.; Methodology, S.W., and N.H.; Supervision, O.R., and E.B.-D.; Writing-original draft, S.W.; Writing-review and editing, O.R., M.M., R.W., and E.B.-D. All authors have read and agreed to the published version of the manuscript.

Funding: This research was funded by Israel Chemical Ltd. (grant number 31010201), the Israel Science Foundation (grant number 1780/18), and a startup grant from the Agricultural Research Organization, Volcani Center, held by Offer Rozenstein.

Acknowledgments: The authors wish to thank the members of the Remote Sensing Laboratory at Tel Aviv University for their support in different stages of the project, and the contribution of the Action 
CA17134 SENSECO (Optical synergies for spatiotemporal sensing of scalable ecophysiological traits) funded by COST (European Cooperation in Science and Technology, www.cost.eu).

Conflicts of Interest: The authors declare no conflict of interest.

\section{References}

1. MacDonald, J.D. Temperature and Water Stress Effects on Sporangium Viability and Zoospore Discharge in Phytophthora cryptogea and P. megasperma. Phytopathology 1978, 68, 1449. [CrossRef]

2. Sade, N.; Gebretsadik, M.; Seligmann, R.; Schwartz, A.; Wallach, R.; Moshelion, M. The role of tobacco Aquaporin1 in improving water use efficiency, hydraulic conductivity, and yield production under salt stress. Plant Physiol. 2010, 152, 245-254. [CrossRef]

3. Robinson, J.B.D. Nutrient Deficiencies and Toxicities in Crop Plants. Exp. Agric. 1995, 31, 391. [CrossRef]

4. Lloyd, J. Plant Health Care for Woody Ornamentals: A Professional's Guide to Preventing and Managing Environmental Stresses and Pests; Cooperative Extension Service, College of Agricultural, Consumer and Environmental Sciences, University of Illinois at Urbana-Champaign: Urbana, IL, USA, 1997; ISBN 1883097177.

5. Al-Sohaibani, S.A.; Mahmoud, M.A.; Al-Othman, M.R.; Ragab, M.M.M.; Saber, M.M.; Abd El-Aziz, A.R.M. Influence of some biotic and abiotic inducers on root rot disease incidence of sweet basil. Afr. J. Microbiol. Res. 2011, 5, 3628-3639. [CrossRef]

6. Kühn, J.; Rippel, R.; Schmidhalter, U. Abiotic soil properties and the occurrence of Rhizoctonia crown and root rot in sugar beet. J. Plant. Nutr. Soil Sci. 2009, 172, 661-668. [CrossRef]

7. Whipker, B.E.; Evans, M.R. Regulation of plant growth. In Greenhouse Operation and Management; Nelson, P.V., Ed.; Pearson Prentice Hall: Upper Saddle River, NJ, USA, 2012; pp. 373-389.

8. Duniway, J.M. Movement of Zoospores of Phytophthora cryptogea in Soils of Various Textures and Matric Potentials. Phytopathology 1976, 66, 877. [CrossRef]

9. le Maire, G.; François, C.; Soudani, K.; Berveiller, D.; Pontailler, J.Y.; Bréda, N.; Genet, H.; Davi, H.; Dufrêne, E. Calibration and validation of hyperspectral indices for the estimation of broadleaved forest leaf chlorophyll content, leaf mass per area, leaf area index and leaf canopy biomass. Remote Sens. Environ. 2008, 112, 3846-3864. [CrossRef]

10. Bartholomeus, H.; Kooistra, L.; Stevens, A.; van Leeuwen, M.; van Wesemael, B.; Ben-Dor, E.; Tychon, B. Soil Organic Carbon mapping of partially vegetated agricultural fields with imaging spectroscopy. Int. J. Appl. Earth Obs. Geoinf. 2011, 13, 81-88. [CrossRef]

11. Horler, D.N.H.; Dockray, M.; Barber, J. The red edge of plant leaf reflectance. Int. J. Remote Sens. 1983, 4, 273-288. [CrossRef]

12. Curran, P.J.; Windham, W.R.; Gholz, H.L. Exploring the relationship between reflectance red edge and chlorophyll concentration in slash pine leaves. Tree Physiol. 1995, 15, 203-206. [CrossRef]

13. Peñuelas, J.; Gamon, J.A.; Fredeen, A.L.; Merino, J.; Field, C.B. Reflectance indices associated with physiological changes in nitrogen- and water-limited sunflower leaves. Remote Sens. Environ. 1994, 48, 135-146. [CrossRef]

14. Gazala, I.F.S.; Sahoo, R.N.; Pandey, R.; Mandal, B.; Gupta, V.K.; Singh, R.; Sinha, P. Spectral reflectance pattern in soybean for assessing yellow mosaic disease. Indian J. Virol. 2013, 24, 242-249. [CrossRef] [PubMed]

15. Zhang, F.; Zhou, G. Estimation of vegetation water content using hyperspectral vegetation indices: A comparison of crop water indicators in response to water stress treatments for summer maize. BMC Ecol. 2019, 19, 1-12. [CrossRef]

16. Ballester, C.; Brinkhoff, J.; Quayle, W.C.; Hornbuckle, J. Monitoring the effects of water stress in cotton using the green red vegetation index and red edge ratio. Remote Sens. 2019, 11. [CrossRef]

17. Zhao, D.; Reddy, K.R.; Kakani, V.G.; Reddy, V.R. Nitrogen deficiency effects on plant growth, leaf photosynthesis, and hyperspectral reflectance properties of sorghum. Eur. J. Agron. 2005, 22, 391-403. [CrossRef]

18. Houborg, R.; Boegh, E. Mapping leaf chlorophyll and leaf area index using inverse and forward canopy reflectance modeling and SPOT reflectance data. Remote Sens. Environ. 2008, 112, 186-202. [CrossRef]

19. El-Hendawy, S.; Al-Suhaibani, N.; Hassan, W.; Tahir, M.; Schmidhalter, U. Hyperspectral reflectance sensing to assess the growth and photosynthetic properties of wheat cultivars exposed to different irrigation rates in an irrigated arid region. PLOS ONE 2017, 1-22. [CrossRef]

20. El-Hendawy, S.E.; Al-Suhaibani, N.A.; Hassan, W.M.; Dewir, Y.H. Evaluation of wavelengths and spectral re fl ectance indices for high- throughput assessment of growth, water relations and ion contents of wheat irrigated with saline water. Agric. Water Manag. 2019, 212, 358-377. [CrossRef]

21. Gholizadeh, A.; Mišurec, J.; Kopačková, V.; Mielke, C.; Rogass, C. Assessment of red-edge position extraction techniques: A case study for norway spruce forests using hymap and simulated sentinel-2 data. Forests 2016, 7. [CrossRef]

22. Herrmann, I.; Berenstein, M.; Sade, A.; Karnieli, A.; Bonfil, D.J.; Weintraub, P.G. Spectral monitoring of two-spotted spider mite damage to pepper leaves. Remote Sens. Lett. 2012, 3, 277-283. [CrossRef]

23. Marshall, M.; Thenkabail, P.; Biggs, T.; Post, K. Hyperspectral narrowband and multispectral broadband indices for remote sensing of crop evapotranspiration and its components (transpiration and soil evaporation). Agric. For. Meteorol. 2016, 218-219, 122-134. [CrossRef]

24. Thenkabail, P.S.; Smith, R.B.; De Pauw, E. Hyperspectral vegetation indices and their relationships with agricultural crop characteristics. Remote Sens. Environ. 2000, 71, 158-182. [CrossRef]

25. Gitelson, A.A.; Gritz, Y.; Merzlyak, M.N. Relationships between leaf chlorophyll content and spectral reflectance and algorithms for non-destructive chlorophyll assessment in higher plant leaves. J. Plant Physiol. 2003, 160, 271-282. [CrossRef] 
26. Pacumbaba, R.O.; Beyl, C.A. Changes in hyperspectral reflectance signatures of lettuce leaves in response to macronutrient deficiencies. Adv. Sp. Res. 2011, 48, 32-42. [CrossRef]

27. Pandey, P.; Ge, Y.; Stoerger, V.; Schnable, J.C. High Throughput In vivo Analysis of Plant Leaf Chemical Properties Using Hyperspectral Imaging. Front. Plant Sci. 2017, 8, 1-12. [CrossRef]

28. Leckie, D.G.; Jay, C.; Gougeon, F.A.; Sturrock, R.N.; Paradine, D. Detection and assessment of trees with Phellinus weirii (laminated root rot) using high resolution multi-spectral imagery. Int. J. Remote Sens. 2004, 25, 793-818. [CrossRef]

29. Reynolds, G.J.; Windels, C.E.; MacRae, I.V.; Laguette, S. Remote sensing for assessing rhizoctonia crown and root rot severity in sugar beet. Plant Dis. 2012, 96, 497-505. [CrossRef]

30. Yang, C.; Everitt, J.H.; Fernandez, C.J. Comparison of airborne multispectral and hyperspectral imagery for mapping cotton root rot. Biosyst. Eng. 2010, 107, 131-139. [CrossRef]

31. Weksler, S.; Rozenstein, O.; Haish, N.; Moshelion, M.; Walach, R.; Ben-Dor, E. A hyperspectral-physiological phenomics system: Measuring diurnal transpiration rates and diurnal reflectance. Remote Sens. 2020, 12, 1493. [CrossRef]

32. Halperin, O.; Gebremedhin, A.; Wallach, R.; Moshelion, M. High-throughput physiological phenotyping and screening system for the characterization of plant-Environment interactions. Plant J. 2017, 89, 839-850. [CrossRef]

33. Mahajan, G.R.; Sahoo, R.N.; Pandey, R.N.; Gupta, V.K.; Kumar, D. Using hyperspectral remote sensing techniques to monitor nitrogen, phosphorus, sulphur and potassium in wheat (Triticum aestivum L.). Precis. Agric. 2014, 15, 499-522. [CrossRef]

34. Serbin, S.P.; Dillaway, D.N.; Kruger, E.L.; Townsend, P.A. Leaf optical properties reflect variation in photosynthetic metabolism and its sensitivity to temperature. J. Exp. Bot. 2012, 63, 489-502. [CrossRef]

35. Ullah, S.; Schlerf, M.; Skidmore, A.K.; Hecker, C. Identifying plant species using mid-wave infrared $(2.5-6 \mu \mathrm{m})$ and thermal infrared $(8-14 \mu \mathrm{m})$ emissivity spectra. Remote Sens. Environ. 2012, 118, 95-102. [CrossRef]

36. Tucker, C.J. Red and photographic infrared linear combinations for monitoring vegetation. Remote Sens. Environ. 1979, 8, 127-150. [CrossRef]

37. Gitelson, A.A.; Kaufman, Y.J.; Merzlyak, M.N. Use of a green channel in remote sensing of global vegetation from EOS- MODIS. Remote Sens. Environ. 1996, 58, 289-298. [CrossRef]

38. Gitelson, A.; Merzlyak, M.N. Quantitative estimation of chlorophyll-a using reflectance spectra: Experiments with autumn chestnut and maple leaves. J. Photochem. Photobiol. B Biol. 1994, 22, 247-252. [CrossRef]

39. Daughtry, C.S.T.; Walthall, C.L.; Kim, M.S.; De Colstoun, E.B.; McMurtrey, J.E. Estimating corn leaf chlorophyll concentration from leaf and canopy reflectance. Remote Sens. Environ. 2000, 74, 229-239. [CrossRef]

40. Gitelsona, A.A.; Kaufmanb, Y.J.; Starkc, R.; Rundquist, D. Novel Algorithms for Remote Estimation of Vegetation Fraction. Remote Sens. Environ. 2002, 80, 76-87. [CrossRef]

41. Frampton, W.J.; Dash, J.; Watmough, G.; Milton, E.J. Evaluating the capabilities of Sentinel-2 for quantitative estimation of biophysical variables in vegetation. ISPRS J. Photogramm. Remote Sens. 2013, 82, 83-92. [CrossRef]

42. Milton, N.M.; Ager, C.M.; Eiswerth, B.A.; Power, M.S. Arsenic- and selenium-induced changes in spectral reflectance and morphology of soybean plants. Remote Sens. Environ. 1989, 30, 263-269. [CrossRef]

43. Curran, P.J. Remote sensing of foliar chemistry. Remote Sens. Environ. 1989, 30, 271-278. [CrossRef]

44. Fletcher, R.S.; Skaria, M.; Escobar, D.E.; Everitt, J.H. Field spectra and airborne digital imagery for detecting phytophthora foot rot infections in citrus trees. HortScience 2001, 36, 94-97. [CrossRef]

45. Zhang, T.T.; Zeng, S.L.; Gao, Y.; Ouyang, Z.T.; Li, B.; Fang, C.M.; Zhao, B. Using hyperspectral vegetation indices as a proxy to monitor soil salinity. Ecol. Indic. 2011, 11, 1552-1562. [CrossRef] 